\title{
Systematic Relationships of Hynobius okiensis among Japanese Salamanders (Amphibia: Caudata)
}

\section{$\operatorname{AUTHOR}(\mathrm{S}):$}

Matsui, Masafumi; Nishikawa, Kanto; Misawa, Yasuchika; Tanabe, Shingo

\section{CITATION:}

Matsui, Masafumi ... [et al]. Systematic Relationships of Hynobius okiensis among Japanese Salamanders (Amphibia: Caudata). Zoological Science 2007, 24(7): 746-751

\section{ISSUE DATE:}

2007-07

URL:

http://hdl.handle.net/2433/85321

RIGHT:

(c) 日本動物学会 / Zoological Society of Japan 


\title{
Systematic Relationships of Hynobius okiensis among Japanese Salamanders (Amphibia: Caudata)
}

\author{
Masafumi Matsui $^{1 *}$, Kanto Nishikawa ${ }^{1}$, Yasuchika Misawa $^{2}$ \\ and Shingo Tanabe ${ }^{3}$ \\ ${ }^{1}$ Graduate School of Human and Environmental Studies, Kyoto University, Yoshida, \\ Sakyo-ku, Kyoto 606-8501, Japan \\ ${ }^{2}$ Civil Engineering and Eco-Technology Consultants, Higashi-ikebukuro 2-23-2, \\ Toshima-ku, Tokyo 170-0013, Japan \\ ${ }^{3}$ Kamikatsura-Higashi-no-Kuchi-Cho, Nishikyo-ku, Kyoto 615-8221, Japan
}

\begin{abstract}
We conducted an electrophoretic survey to examine systematic relationships of a lotic-breeding salamander Hynobius okiensis endemic to Dogo Island of the Oki Islands, Japan, with several lentic and lotic-breeding Japanese species. Genetically $\boldsymbol{H}$. okiensis with $\mathbf{2 n = 5 6}$ chromosomes was closer to the lentic-breeding $H$. nebulosus group $(H$. nebulosus and $H$. dunni) with the same chromosome number than to the lotic-breeding $H$. naevius group $(H$. naevius and $H$. kimurae) and $H$. boulengeri with 58 chromosomes. Chromosome number reduction from 58 to 56 , possibly accompanied with a change in breeding environment from streams to still waters, is estimated to have first occurred in the nebulosus group of Hynobius. A reversal only in breeding habits then seems to have followed in steep, montane environments of the small island of Dogo, resulting in the speciation of $H$. okiensis.
\end{abstract}

Key words: allozyme electrophoresis, biochemical systematics, chromosome number, Hynobiidae, phylogeny

\section{INTRODUCTION}

The Oki salamander, Hynobius okiensis Sato, 1940, occurs on Dogo Island, the largest of the Oki Island Group, in the Japan Sea, $80 \mathrm{~km}$ off the coast of Shimane in the San'in District of mainland Honshu (Matsui, 1997). The island is nearly circular in shape, with a diameter of about $17-18 \mathrm{~km}$, and because the salamander is endemic to this limited area, it has been listed as a threatened species in IUCN (IUCN, 1996) and the Japanese Red Data Book (Matsui, 2000).

There are two groups in Hynobius that exhibit different modes of breeding (i.e., lentic and lotic). Hynobius okiensis was originally described as a member of the lotic-breeding $H$. naevius group (Sato, 1940) that includes $H$. naevius (Temminck and Schlegel, 1838), H. kimurae Dunn, 1923, and $H$. stejnegeri Dunn, 1923, because of its streamdwelling larvae and stout body and clearly marked dorsum in adults.

Sato (1940), however, noted that $H$. okiensis showed some characteristics of the lentic-breeding $H$. nebulosus group, such as absence of claws on the tips of the digits in larvae, and posteriorly compressed tail, long and fragile limbs, and presence of a small protuberance at the anterior tip of the vent in adult males. He also recognized in skull characteristics of $H$. okiensis intermediate conditions bet-

\footnotetext{
* Corresponding author. Phone: +81-75-753-6846; Fax : +81-75-753-2891; E-mail: fumi@zoo.zool.kyoto-u.ac.jp
}

ween the two groups, and concluded that $H$. okiensis is closest to the nebulosus group among species of the naevius group.

In his original description, Sato (1940) illustrated a karyotype obtained by sectioning, but did not mention it in the text. Later, Seto et al. (1987) obtained a Giemsa-stained karyotype for this species and determined the diploid chromosome number to be $2 n=56$ like all species of lentic breeding Japanese Hynobius (Seto et al., 1988), instead of 58 chromosomes as in the lotic breeders (lizuka and Kakegawa, 1989). Viable $\mathrm{F} 1$ hybrids between female $H$. okiensis and male $H$. nebulosus were artificially obtained by Ouji et al. (1986), but there have been no additional reports since then. No additional studies have been done on other aspects, either, and the systematic relationships of $H$. okiensis remained unresolved.

Studies of Japanese small salamanders of the genus Hynobius have demonstrated that electrophoresis is particularly useful for clarifying the taxonomic status and systematic relationships of these animals (e.g., Matsui, 1987; Matsui et al., 2001, 2002, 2006). This study provides electrophoretic evidence that indicates closer affinity of $H$. okiensis to $H$. nebulosus than to $H$. naevius, and discusses the evolution of breeding habits among Japanese Hynobius.

\section{MATERIALS AND METHODS}

Because populations of many Japanese small salamanders are in decline, and especially because $H$. okiensis is listed in the Red Data Books, we should refrain from collecting large numbers of specimens. Bearing this in mind, we used a total of 66 salamanders (eight populations): $H$. okiensis from Dogo (=Oki) island, Shimane 
Prefecture (Populations 1-3); two lentic-breeding salamanders with $2 \mathrm{n}=56$ chromosomes $[H$. nebulosus from Izumo-shi, Shimane Prefecture (Population 4) and $H$. dunni Tago, 1931 from Bungotakada-shi, Oita Prefecture (Population 5)]; and three lotic-breeding salamanders with $2 n=58$ chromosomes $[H$. naevius from Unnan-shi, Shimane Prefecture (Population 6), H. kimurae from Unnan-shi, Shimane Prefecture (Population 7), and $H$. boulengeri (Thompson, 1912) from Kamikitayama-mura, Nara Prefecture (Population 8)]. The samples of $H$. kimurae and $H$. naevius were syntopic (Fig. 1).

Following Nishikawa et al. (2001), we used larvae in addition to metamorphs, because larvae are much easier to collect and place less sampling pressure on natural populations than metamorphs. To minimize the underestimation of genetic variation (Nishikawa et al., 2001), we randomly collected eggs or larvae from different water bodies in a locality and reared them to Stages 63 to 66 of Iwasawa and Yamashita (1991).

Samples of liver were removed from anesthetized salamanders and maintained frozen at $-84^{\circ} \mathrm{C}$ until use for electrophoresis. Voucher specimens were fixed in $10 \%$ formalin, later preserved in $70 \%$ ethanol for metamorphs and $50 \%$ ethanol for larvae, and stored in the Graduate School of Human and Environmental Studies, Kyoto University (KUHE) or Mr. Okada's (O) or Mr. Tanabe's (T) private collections (see Appendix 1). We analyzed homogenized tissue extracts by standard horizontal starch gel electrophoresis (Murphy et al., 1996) at a concentration of $11.5 \%$. We scored the products of 24 loci encoding 17 allozymes for all individuals, as shown in Table 1.
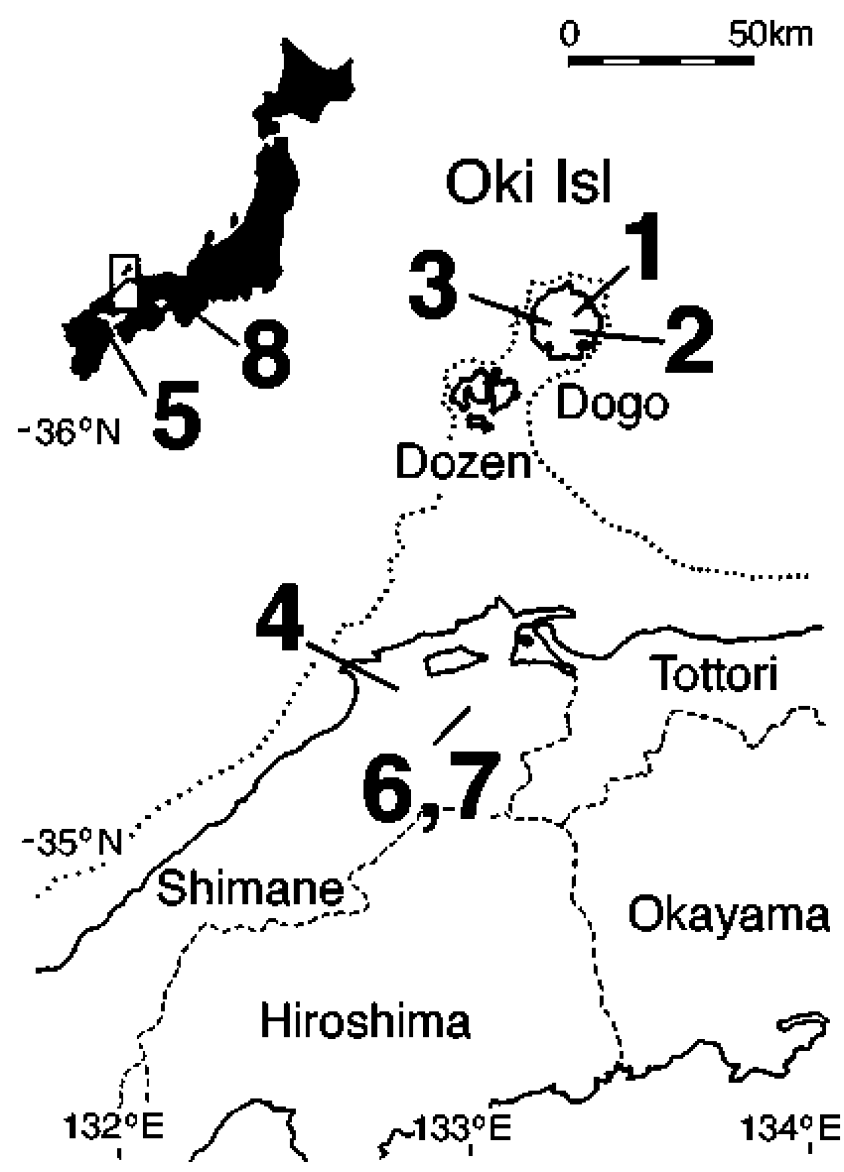

Fig. 1. Map of the Chugoku district of Honshu, Japanese mainland, showing sampling localities for the Hynobius species used in this study. Dotted line indicates the $100-m$ depth contour. For sample numbers, refer to text.
Table 1. Enzymes, E. C. number, locus notation, and buffer systems used in the analyses of allozyme variations in Hynobius species. Buffer systems- CAPM6: Citrate-aminopropylmorpholine, $\mathrm{pH}=6.0$ (Clayton and Tretiak, 1972), TC7: Tris-citrate, $\mathrm{pH}=7.0$ (Shaw and Prasad, 1970), TC8: Tris-citrate, $\mathrm{pH}=8.0$ (Clayton and Tretiak, 1972), TBE8.7: Tris-borate-EDTA, $\mathrm{pH}=8.7$ (Boyer et al., 1963). ${ }^{*}$ NADP-dependent malate dehydrogenase.

\begin{tabular}{llll}
\hline \multicolumn{1}{c}{ Enzyme } & $\begin{array}{l}\text { E.C. } \\
\text { number }\end{array}$ & Locus & $\begin{array}{l}\text { Buffer } \\
\text { system }\end{array}$ \\
\hline Aconitate hydratase & 4.2 .1 .3 & mACOH-A & TC8 \\
Aconitate hydratase & 4.2 .1 .3 & sACOH-A & TC8 \\
Aspartate transaminase & 2.6 .1 .1 & mATA-A & CAPM6 \\
Aspartate transaminase & 2.6 .1 .1 & sATA-A & CAPM6,TC7 \\
Fumarate hydratase & 4.2 .1 .2 & FUMH-A & TBE8.7 \\
Glucose-6-phosphate isomerase & 5.3 .1 .9 & GPI-A & CAPM6 \\
Glutamate dehydrogenase & 1.4 .1 .3 & GTDH-A & TC8 \\
Glycerol-3-phosphate dehydrogenase & 1.1 .1 .8 & G3PDH-A & TC8 \\
3-Hydroxybutyrate dehydrogenase & 1.1 .1 .30 & HBDH-A & CAPM6 \\
Isocitrate dehydrogenase & 1.1 .1 .42 & mIDH-A & TC7 \\
Isocitrate dehydrogenase & 1.1 .1 .42 & sIDH-A & TC7 \\
L-Lactate dehydrogenase & 1.1 .1 .27 & LDH-A & CAPM6,TC7 \\
L-Lactate dehydrogenase & 1.1 .1 .27 & LDH-B & CAPM6,TC7 \\
Malate dehydrogenase & 1.1 .1 .37 & mMDH-A & CAPM6,TC8 \\
Malate dehydrogenase & 1.1 .1 .37 & SMDH-A & CAPM6,TC8 \\
Malic enzyme & 1.1 .1 .40 & mMDHP-A & TC7 \\
Malic enzyme & 1.1 .1 .40 & SMDHP-A & TC7 \\
Peptidase (leucyl-alanine) & $3.4 .11 .-$ & PEP-la & TBE8.7 \\
Peptidase (leucyl-glycine) & $3.4 .11 .-$ & PEP-lg & TBE8.7 \\
Phosphoglucomutase & 5.4 .2 .2 & PGM-A & TC7 \\
Phosphoglucomutase & 5.4 .2 .2 & PGM-C & TC7 \\
Phosphogluconate dehydrogenase & 1.1 .1 .44 & PGDH-A & TC7 \\
Sorbitol dehydrogenase & 1.1 .1 .14 & SDH-A & CAPM6 \\
Superoxide dismutase & 1.15 .1 .1 & sSOD-A & TBE8.7 \\
\hline
\end{tabular}

Genetic interpretations of allozyme data follow Nishikawa et al. (2001). Enzyme nomenclature, E. C. numbers, and the notation of loci, electromorphs, and genotypes mainly follow Murphy et al. (1996) and IUBMB (1992). Electromorphs were designated by letters, with "a" representing the most rapidly migrating variant.

We calculated all statistics using the BIOSYS-1 computer program (Swofford and Selander, 1981) and computed standard estimates of genetic variability, i.e., mean heterozygosity by direct count $(H)$, proportion of polymorphic loci $(P)$, and the mean number of electromorphs per locus $(A)$, for each sample.

To estimate overall genetic differentiation among samples, we used Nei's (1978) unbiased genetic distance (D) and Cavalli-Sforza and Edwards' (1967) chord distance. Wiens (2000) reported that in the analyses of data sets that include polymorphic characters, such as allozymes, distance and maximum likelihood methods are superior to some kinds of simple parismony analyses. We thus estimated genetic relationships among species by a neighbor-joining (NJ) analysis (Saitou and Nei, 1987) using Cavalli-Sforza and Edwards' (1967) chord distances, and by a maximum likelihood (ML) analysis employing Felsenstein's (1993) CONTML algorithm. We rooted NJ and $\mathrm{ML}$ trees with the outgroup $H$. boulengeri (Population 8), because this species was originally described as a distinct genus, Pachypalaminus (Thompson, 1912), and this classification was followed until recently (see Nishio et al., 1987). This species thus appears to be well differentiated from the remaining Japanese Hynobius species. We tested the degree of support for nodes of the resultant trees by 1,000 nonparametric bootstrap pseudoreplicates (Felsenstein, 1985). We performed these analyses with PHYLIP vers. 3.5 C (Felsenstein, 1993).

\section{RESULTS}

Of the 24 presumptive loci examined in all individuals, 
Table 2. Allele frequencies at 20 polymorphic loci among samples studied. For population number, refer to text.

\begin{tabular}{|c|c|c|c|c|c|c|c|c|c|c|}
\hline \multirow[b]{2}{*}{ Locus } & \multirow[b]{2}{*}{ Allele } & \multirow{2}{*}{$\begin{array}{l}\text { Species } \\
\text { Population } \\
\text { (n) }\end{array}$} & \multicolumn{3}{|c|}{ Hynobius okiensis } & \multirow{2}{*}{$\begin{array}{c}H . \\
\text { nebulosus } \\
4 \\
(12)\end{array}$} & \multirow{2}{*}{$\begin{array}{c}\text { H. } \\
\text { dunni } \\
5 \\
(9)\end{array}$} & \multirow{2}{*}{$\begin{array}{c}H . \\
\text { naevius } \\
6 \\
(6)\end{array}$} & \multirow{2}{*}{$\begin{array}{c}H . \\
\text { kimurae } \\
7 \\
(16)\end{array}$} & \multirow{2}{*}{$\begin{array}{c}H . \\
\text { boulengeri } \\
8 \\
(10)\end{array}$} \\
\hline & & & $\begin{array}{c}1 \\
(8)\end{array}$ & $\begin{array}{c}2 \\
(3)\end{array}$ & $\begin{array}{c}3 \\
(2)\end{array}$ & & & & & \\
\hline \multirow[t]{3}{*}{$\overline{\mathrm{mACOH}-\mathrm{A}}$} & $\mathrm{a}$ & & & & & & & 1.000 & 0.969 & \\
\hline & $b$ & & 0.938 & 0.667 & 0.750 & 1.000 & 1.000 & & 0.031 & 1.000 \\
\hline & c & & 0.062 & 0.333 & 0.250 & & & & & \\
\hline \multirow[t]{2}{*}{ sACOH-A } & a & & & & & 1.000 & & 1.000 & 1.000 & 1.000 \\
\hline & b & & 1.000 & 1.000 & 1.000 & & 1.000 & & & \\
\hline \multirow[t]{2}{*}{ mATA-A } & a & & 0.563 & 0.500 & 0.750 & 1.000 & & 1.000 & 1.000 & 1.000 \\
\hline & b & & 0.437 & 0.500 & 0.250 & & 1.000 & & & \\
\hline sATA-A & a & & 0.187 & 0.500 & 0.250 & & 1.000 & & & 0.150 \\
\hline & b & & 0.813 & 0.500 & 0.750 & 1.000 & & 1.000 & & 0.850 \\
\hline & c & & & & & & & & 1.000 & \\
\hline FUMH-A & a & & 0.062 & & & & 0.056 & & & 0.900 \\
\hline & $b$ & & 0.813 & 1.000 & 1.000 & 1.000 & 0.944 & 1.000 & 0.844 & 0.100 \\
\hline & c & & 0.125 & & & & & & 0.156 & \\
\hline GPI-A & a & & & & & & & 0.833 & & \\
\hline & $b$ & & 0.938 & 1.000 & 1.000 & 0.125 & & 0.167 & 1.000 & 1.000 \\
\hline & c & & 0.062 & & & 0.875 & 1.000 & & & \\
\hline G3PDH-A & a & & & & & & & & 0.062 & \\
\hline & b & & 1.000 & 1.000 & 1.000 & 1.000 & 1.000 & 1.000 & 0.938 & 1.000 \\
\hline $\mathrm{HBDH}-\mathrm{A}$ & a & & & 0.167 & 0.250 & & & & & \\
\hline & $b$ & & 1.000 & 0.833 & 0.750 & 1.000 & & & & \\
\hline & c & & & & & & 0.944 & 1.000 & 1.000 & \\
\hline & $d$ & & & & & & 0.056 & & & 1.000 \\
\hline sIDH-A & a & & & & & & 1.000 & & & \\
\hline & b & & & & & & & & 1.000 & \\
\hline & c & & 1.000 & 1.000 & 1.000 & & & 1.000 & & \\
\hline & d & & & & & 1.000 & & & & 1.000 \\
\hline LDH-A & a & & & & & & & 1.000 & & \\
\hline & b & & 1.000 & 1.000 & 1.000 & 1.000 & 1.000 & & 1.000 & 1.000 \\
\hline LDH-B & a & & 0.750 & 1.000 & 1.000 & 0.083 & & & & \\
\hline & b & & 0.250 & & & 0.917 & & 0.833 & & 0.050 \\
\hline & c & & & & & & & 0.167 & 1.000 & 0.950 \\
\hline & $d$ & & & & & & 1.000 & & & \\
\hline $\mathrm{mMDH}-\mathrm{A}$ & a & & & & & 1.000 & 0.056 & & & \\
\hline & $b$ & & 1.000 & 1.000 & 1.000 & & 0.944 & 1.000 & 1.000 & 1.000 \\
\hline sMDH-A & a & & & & & & & & & 1.000 \\
\hline & $\mathrm{b}$ & & & & & & & & 1.000 & \\
\hline & c & & & & & & 1.000 & & & \\
\hline & $d$ & & 0.938 & 1.000 & 1.000 & 1.000 & & 1.000 & & \\
\hline & e & & 0.062 & & & & & & & \\
\hline mMDHP-A & a & & & & & & & & 1.000 & \\
\hline & $b$ & & & & & 0.750 & 1.000 & 1.000 & & \\
\hline & c & & 1.000 & 1.000 & 1.000 & 0.250 & & & & 1.000 \\
\hline sMDHP-A & a & & 0.250 & 0.167 & 0.250 & & & & & \\
\hline & b & & 0.750 & 0.833 & 0.750 & 1.000 & 1.000 & 1.000 & 1.000 & \\
\hline & c & & & & & & & & & 1.000 \\
\hline PEP-la & a & & 1.000 & 1.000 & 1.000 & 1.000 & 1.000 & 1.000 & 1.000 & 0.800 \\
\hline & $b$ & & & & & & & & & 0.200 \\
\hline PGM-A & a & & & & & 0.083 & & & & \\
\hline & $b$ & & 1.000 & 1.000 & 1.000 & 0.917 & 1.000 & 1.000 & 1.000 & 1.000 \\
\hline PGM-C & a & & & & & & & & & 1.000 \\
\hline & b & & 1.000 & 1.000 & 1.000 & & 0.056 & 1.000 & & \\
\hline & c & & & & & 0.833 & 0.500 & & 1.000 & \\
\hline & $d$ & & & & & 0.167 & 0.444 & & & \\
\hline PGDH-A & a & & & & & & & & 0.094 & 0.750 \\
\hline & $b$ & & 1.000 & 1.000 & 1.000 & 0.167 & 0.111 & & & \\
\hline & c & & & & & 0.833 & 0.889 & 1.000 & 0.906 & 0.250 \\
\hline sSOD-A & a & & 1.000 & 1.000 & 1.000 & 0.208 & & & & \\
\hline & b & & & & & 0.792 & & 1.000 & 0.125 & 0.400 \\
\hline & c & & & & & & 1.000 & & 0.875 & 0.600 \\
\hline A & & & 1.4 & 1.2 & 1.2 & 1.3 & 1.3 & 1.1 & 1.2 & 1.3 \\
\hline$P$ & & & 33.3 & 20.8 & 20.8 & 29.2 & 20.8 & 8.3 & 16.7 & 25.0 \\
\hline $\mathrm{H}$ & & & 0.083 & 0.083 & 0.104 & 0.056 & 0.065 & 0.014 & 0.039 & 0.054 \\
\hline
\end{tabular}


Table 3. Matrices of Nei's (1978) unbiased genetic distance (above diagonal) and Cavalli-Sforza and Edwards' (1967) chord distance (below diagonal) among eight populations examined.

\begin{tabular}{|c|c|c|c|c|c|c|c|c|}
\hline \multirow{2}{*}{$\begin{array}{l}\text { Species } \\
\text { Population }\end{array}$} & \multicolumn{3}{|c|}{ Hynobius okiensis } & \multirow{2}{*}{$\begin{array}{c}H . \\
\text { nebulosus } \\
4\end{array}$} & \multirow{2}{*}{$\begin{array}{c}H . \\
\text { dunni } \\
5\end{array}$} & \multirow{2}{*}{$\begin{array}{c}H . \\
\text { naevius } \\
6\end{array}$} & \multirow{2}{*}{$\begin{array}{c}H . \\
\text { kimurae } \\
7\end{array}$} & \multirow{2}{*}{$\begin{array}{c}H . \\
\text { boulengeri } \\
8\end{array}$} \\
\hline & 1 & 2 & 3 & & & & & \\
\hline 1 & - & 0.002 & 0.000 & 0.390 & 0.518 & 0.457 & 0.630 & 0.514 \\
\hline 2 & 0.132 & - & 0.000 & 0.440 & 0.495 & 0.474 & 0.611 & 0.555 \\
\hline 3 & 0.129 & 0.053 & - & 0.409 & 0.530 & 0.442 & 0.595 & 0.513 \\
\hline 4 & 0.487 & 0.519 & 0.510 & - & 0.490 & 0.348 & 0.514 & 0.488 \\
\hline 5 & 0.562 & 0.562 & 0.574 & 0.555 & - & 0.594 & 0.509 & 0.725 \\
\hline 6 & 0.544 & 0.559 & 0.551 & 0.498 & 0.607 & - & 0.431 & 0.661 \\
\hline 7 & 0.618 & 0.619 & 0.616 & 0.567 & 0.566 & 0.520 & - & 0.505 \\
\hline 8 & 0.575 & 0.591 & 0.583 & 0.546 & 0.630 & 0.602 & 0.552 & - \\
\hline
\end{tabular}

GTDH-A, mIDH-A, PEP-Ig, and SDH-A were fixed identically in all samples. The remaining 20 loci were all polymorphic (Table 2); the most variable locus was $\mathrm{SMDH}-\mathrm{A}$, with five alleles, and next were HBDH-A, sIDH-A, LDH-B, and PGM$C$, each with four alleles. The mean number of electromorphs per locus $(A)$ varied from 1.1-1.4, the percentage of polymorphic loci $(\mathrm{P})$ from 8.3-33.3, and the mean heterozygosity $(H)$ from $0.014-0.104$. The highest values in $A$ and $P$ and in $\mathrm{H}$ were found for Populations 1 and 3 , respectively, while Population 6 exhibited lowest variability in $A, P$, and $H$.

We detected four unique alleles, mACOH-A (c), $\mathrm{HBDH}-$ A (a), sMDH-A (e), and sMDHP-A (a), in the samples of $H$. okiensis (Populations 1-3); one unique allele in $H$. nebulosus [Population 4: PGM-A (a)]; three in H. dunni [Population 5: sIDH-A (a), LDH-B (d), and SMDH-A (c)]; two in $H$. naevius [Population 6: GPI-A (a) and LDH-A (a)]; five in H. kimurae [Population 7: sATA-A (c), G3PDH-A (a), sIDH-A (b), sMDHA (b), and mMDHP-A (a)]; and four in $H$. boulengeri [Population 8: SMDH-A (a), SMDHP-A (c), PEP-la (b), and PGM-C (a)]. Although $H$. okiensis (Populations 1-3) had four unique alleles, their frequencies were low (from 0.062 to 0.333 ). Similarly, $H$. nebulosus had no fixed locus with unique allele. In contrast, the remaining species had some fixed loci with unique alleles (one in $H$. naevius, three in $H$. dunni and $H$. boulengeri, and four in $H$. kimurae).

As shown in Table 3, Nei's (1978) and Cavalli-Sforza and Edwards' (1967) distances were large and indicated substantial differentiation among species, but the three localities of $H$. okiensis (Populations 1-3) were genetically less variable, with Nei's (1978) D between 0.000 and 0.002 . The highest $D$ value and Cavalli-Sforza and Edwards' (1967) chord distance were found between Populations 5 $(H$. dunni) and $8(H$. boulengeri). Among the six species compared, $H$. okiensis was closest to $H$. nebulosus in both Nei's D (0.390-0.440, mean $=0.413)$ and Cavalli-Sforza and Edwards' (1967) chord distance.

Although the bootstrap support for each cluster was low $(<50 \%)$, except for high values $(>90 \%)$ for the cluster including the three populations of $H$. okiensis, the topologies of $\mathrm{ML}$ and $\mathrm{NJ}$ trees were similar, and only the $\mathrm{ML}$ tree is shown in Fig. 2. The two trees differed only in the positions of $H$. nebulosus and $H$. dunni. In the ML tree, the cluster including the three populations of $H$. okiensis showed a sister-group relationship with $H$. nebulosus and next with $H$. dunni, but this order was reversed in the NJ tree. This cluster, including $H$. okiensis, $H$. nebulosus, and $H$. dunni, successively joined



Fig. 2. ML tree rooted by the outgroup H. boulengeri (Population 8). For the locations indicated by sample numbers, refer to text and Fig. 1.

with $H$. naevius, $H$. kimurae, and $H$. boulengeri.

\section{DISCUSSION}

Since the original description by Sato (1940), H. okiensis has been considered to be a member of the naevius group; in an extreme view, Nakamura and Uéno (1963) considered $H$. okiensis and $H$. kimurae as subspecies of $H$. naevius, although Sato $(1940,1943)$ himself had noted an affinity of $H$. okiensis to the nebulosus group. Unbiased Nei's (1978) genetic distances between $H$. okiensis and $H$. naevius, ranging from $0.457-0.474$, are much higher than those reported among sister species of Japanese salamanders and newts ( $D=0.22$ : Matsui, 1987; Hayashi and Matsui, 1988). The present electrophoretic data indicate $H$. okiensis not to be conspecific with $H$. naevius, supporting Sato's (1940) original taxonomic assignment.

Hynobius okiensis had the smallest genetic distances from $H$. nebulosus among the five species compared (mean Nei's $D=0.413)$. This value is much higher than conspecific levels (see above), and further, $H$. okiensis possessed four exclusive alleles, indicating significant unique differentiation from other species. From these lines of evidence, there is no doubt in retaining $H$. okiensis as a valid species.

In the two analyses of inter-sample relationships, samples of $H$. okiensis formed a distinct cluster that was grouped with $H$. nebulosus and $H$. dunni. This finding also supports $H$. okienis as a closer relative of lentic-breeding $H$. nebulosus and $H$. dunni than of lotic-breeding $H$. naevius or H. kimurae.

This result suggests that lotic-breeding $H$. okiensis shares a common ancestor with lentic-breeding $H$. nebulosus and $H$. dunni, and has secondarily acquired the habit of breeding in streams. This idea conforms well to the karyo- 
logical evidence that $H$. okiensis has $2 n=56$ chromosomes, like $H$. nebulosus and $H$. dunni, but unlike $H$. naevius, $H$. kimurae, or $H$. boulengeri, which all have 58 chromosomes (Seto et al., 1987).

The close affinity of lotic-breeding $H$. okiensis with lentic-breeding $H$. nebulosus and $H$. dunni implies that ecological differences like breeding habits do not always reflect phylogenetic relationships among hynobiid salamanders. In fact, $H$. tsuensis Abe, 1922 from Tsushima Island is generally regarded as a close relative of $H$. nebulosus, but is actually a lotic breeder (Sato, 1943). Thus, changes in breeding habits appear to have occurred in different lineages independently of karyotypic evolution in Japanese small salamanders.

There are no fossil data to estimate the accurate time of divergence. However, if we adopt the correlation between $D$ values and time of separation in amphibians [maximum, $1 D=14$ MY (Maxson and Maxson, 1979; Hayashi and Matsui, 1988); minimum, 1D=10 MY (Beerli et al., 1996)], the ancestors of $H$. okiensis and $H$. nebulosus, with minimum Nei's $D=0.390$, are estimated to have diverged at approximately 5.5-3.9 Ma (Upper Miocene-Middle Pliocene; Estes, 1981). An accurate geological history of the formation of the Oki islands is unfortunately not available, but the islands are generally considered to have formed by the Middle Miocene (ca. 10-15 Ma) through volcanic activity (Igi et al., 1987). This limited geological information does not contradict the date of divergence estimated above. On the other hand, the islands seem to have been connected with the adjacent Honshu mainland through lowlands until they were separated by Oki Strait, which is estimated to have formed about 16,000 years BP (Ohshima, 1990).

Zhao and Hu (1988) suggested a reduction in chromosome number occurred from 78 in Onychodacylus through 62 in Salamandrella to 58, 56, and 40 in Hynobius, although the most recent phylogenetic hypothesis for the family Hynobiidae based on DNA sequences (Zhang et al., 2006) does not consistently support Zhao and Hu's (1988) hypothesis. Within the genus Hynobius, the general evolutionary trend in chromosome number observed in the family seems to apply, as far as the species treated here are concerned.

A chromosome-number reduction from 58 to 56 , possibly accompanied by a change in breeding habit from streams to still waters, is estimated to have occurred in the common ancestor of the nebulosus group by the Upper Miocene. Then, probably by the Middle Pliocene, a reversal in breeding habits in this group would have been achieved by the ancestor of $H$. okiensis that invaded steep, montane habitats of the small island of Dogo. This ancestral stock, through acquiring lotic breeding, would have been ecologically isolated from the lentic-breeding sister stock that might have occupied the lowlands connecting the island and mainland Honshu until the recent loss of the land connection. Additionally, divergence of the ancestral $H$. okiensis from the sister stock would have been promoted by the sea level fluctuations that occurred through the Pliocene to Pleistocene. Such fluctuations would have been unfavorable for stable population settlements of the lentic breeders on the connecting lowlands. To verify these assumptions, further studies including other species of Japanese Hynobius are necessary.

\section{ACKNOWLEDGMENTS}

We thank T. Seto, M. Notsu, T. Hayashi, S. Okada, and T. Sugahara for help in collecting specimens. This work was supported by a Grant-in-Aid to MM (No. 11640697) from the Ministry of Education, Science, Sports and Culture, Japan, through the Japan Society for the Promotion of Science and grants from the Environment Agency of Japan (now the Ministry of Environment) and Japanese Society for the Protection of Fishery Resources.

\section{REFERENCES}

Beerli P, Hotz H, Uzzell T (1996) Geologically dated sea barriers calibrate a protein clock for Aegean water frog. Evolution 50: 1676-1687

Boyer SH, Fainer DC, Watson-Williams EJ (1963) Lactate dehydrogenase variation from human blood: evidence for molecular subunits. Science 141: 642-643

Cavalli-Sforza LA, Edwards AWF (1967) Phylogenetic analysis: models and estimation procedures. Evolution 21: 550-570

Clayton JW, Tretiak DN (1972) Amine-citrate buffers for $\mathrm{pH}$ control in starch gel electrophoresis. J Fish Res Board Can 29: 11691172

Estes R (1981) Gymnophiona, Caudata. Handbuch der Paleoherpetologie 2. Gustav Fischer, Stuttgart

Felsenstein J (1985) Confidence limits on phylogenies: an approach using the bootstrap. Evolution 39: 783-791

Felsenstein J (1993) PHYLIP (Phylogeny Inference Package) Version 3.5c. Department of Genetics, University of Washington, Seattle

Hayashi T, Matsui M (1988) Biochemical differentiation in Japanese newts, genus Cynops (Salamandridae). Zool Sci 5: 1121-1136

Igi S, Murakami N, Okubo M (1987) Regional Geology of Japan. Pt 7. Chugoku. Kyoritsu Shuppan, Tokyo (in Japanese)

lizuka K, Kakegawa M (1989) Comparative karyology in five species of hynobiid salamanders from Taiwan and Japan. In "Current Herpetology in East Asia" Ed by M Matsui, T Hikida, RC Goris, Herpetol Soc Jpn, Kyoto, pp 95-105

IUBMB (International Union of Biochemistry and Molecular Biology) (1992) Enzyme Nomenclature 1992. Academic Press, San Diego

IUCN (International Union for Conservation of Nature and Natural Resources) (1996) 1996 IUCN Red List of Threatened Animals. IUCN, Gland, Switzerland and Cambridge, UK

Iwasawa H, Yamashita K (1991) Normal stages of development of a hynobiid salamander, Hynobius nigrescens Stejneger. Jpn J Herpetol 14: 39-62 (in Japanese)

Matsui M (1987) Isozyme variation in salamanders of the nebulosuslichenatus complex of the genus Hynobius from eastern Honshu, Japan, with a description of a new species. Jpn J Herpetol 12: $50-64$

Matsui M (1997) Hynobius okiensis. In "Basic Data on Rare Aquatic Wildlife of Japan (IV)" Ed by Japanese Society for the Protection of Fishery Resources, JSPFR, Tokyo, pp 303-308 (in Japanese)

Matsui M (2000) Hynobius okiensis. In "The Red Data Book of Japan - Amphibians and Reptiles 2000" Ed by Environment Agency of Japan, Japan Wildlife Research Center, Tokyo, pp 84-85 (in Japanese)

Matsui M, Nishikawa K, Tanabe S, Misawa Y (2001) Systematic status of Hynobius tokyoensis from Aichi Prefecture, Japan (Amphibia; Urodela). Comp Biochem Physiol B 130: 181-189

Matsui M, Nishikawa K, Misawa Y, Kakegawa M, Sugahara T (2002) Taxonomic relationships of an endangered salamander Hynobius hidamontanus Matsui, 1987 with $H$. tenuis Nambu, 1991 (Amphibia: Caudata). Curr Herpetol 21: 25-34

Matsui M, Nishikawa K, Utsunomiya T, Tanabe S (2006) Geo- 
graphic allozyme variation in the Japanese clouded salamander, Hynobius nebulosus (Amphibia: Urodela). Biol J Linn Soc 89: 311-330

Maxson, LR. Maxson RD (1979) Comparative albumin and biochemical evolution in plethodontid salamanders. Evolution 33: 1057-1062

Murphy RW, Sites JW Jr, Buth DG, Haufler CH (1996) Proteins: Isozyme electrophoresis. In "Molecular Systematics" 2nd ed Ed by DM Hillis, C Moritz, BK Mable, Sinauer Associates, Sunderland, pp 51-120

Nakamura K, Uéno SI (1963) Japanese Reptiles and Amphibians in Colour. Hoikusha, Osaka (in Japanese)

Nei, M (1978) Estimation of average heterozygosity and genetic distance from a small number of individuals. Genetics 89: 583-590

Nishikawa K, Matsui M, Tanabe S, Sato S (2001) Geographic enzyme variation in a Japanese salamander, Hynobius boulengeri Thompson (Amhibia: Caudata). Herpetologica 57: 281-294

Nishio K, Matsui M, Tasumi M (1987) The lacrimal bone in salamanders of the genera Hynobius and Pachypalaminus: a reexamination of its taxonomic significance. Monit Zool Ital (NS) 21: 307-315

Ohshima K, (1990) The history of straits around the Japanese islands in the late-Quaternary. Quaternary Res 29: 193-208 (in Japanese)

Ouji M, Taguchi T, Tsuneki K (1986) Comparative study of hynobiid salamanders in San-in District. San-in Chiiki Kenkyu Shizen Kankyo 2: 35-41 (in Japanese)

Saitou N, Nei M (1987) The neighbor-joining method: a new method for reconstructing phylogenetic trees. Mol Biol Evol 4: 406-425
Sato I (1940) Regarding salamanders from Oki. Zool Mag Tokyo 52 298-309 (in Japanese)

Sato I (1943) A Monograph of the Tailed Batrachians of Japan. Nippon Shuppansha, Osaka (in Japanese)

Seto T, Ouji M, Kuzumi S (1987) Karyotype analysis of Hynobius okiensis Sato, a salamander endemic to Dogo, Oki Islands. San-in Chiiki Kenkyu Shizen Kankyo 3: 1-6 (in Japanese)

Seto T, Matsui M, Kakegawa M (1988) The karyotype of Hynobius hidamontanus, with comments on the karyotypic variation within the nebulosus-lichenatus complex of the genus Hynobius. Jpn J Herpetol 12: 142-146

Shaw CR, Prasad R (1970) Starch gel electrophoresis of enzymes a compilation of recipes. Biochem Genet 4: 297-330

Swofford DL, Selander RB (1981) BIOSYS-1: a FORTRAN program for the comprehensive analysis of electrophoretic data in population genetics and systematics. J Hered 72: 281-283

Thompson JC (1912) Description of a new genus and species of salamander from Japan. Proc Calif Acad Sci Ser 4 3: 183-186

Wiens J (2000) Reconstructing phylogenies from allozyme data: comparing method performance with congruence. Biol J Linn Soc 70: 613-632

Zhang P, Chen YQ, Zhou H, Liu YF, Wang XL, Papenfuss T, Wake DB, Qu LH (2006) Phylogeny, evolution, and biogeography of Asiatic salamanders (Hynobiidae). Proc Natl Acad Sci USA 103: 7360-7365

Zhao EM, Hu QX (1988) Studies on Chinese tailed amphibians. Contrib Herpetol 4: 1-44

(Received December 19, 2006 / Accepted February 7, 2007)

Appendix 1. Material examined. Voucher specimens are stored at the Graduate School of Human and Environmental Studies, Kyoto University (KUHE), in Mr. Okada's private collection (O), or in Mr. Tanabe's private collection ( $T$ ).

Population 1, KUHE 11763-11765, T 2059-2063 (n=8); Population 2, KUHE 18917-18919 ( $n=3$ ); Population 3, KUHE $22776-22777$ ( $n=2$ ); Population 4, KUHE 25781-25782, 10 larvae KUHE unnumbered $(n=12)$; Population 5, KUHE 14351-14352, 14356, 14358, 14366-14367, 14370, 14372-14373 ( $n=9)$; Population 6, KUHE 18832, O 1-5 ( $n=6)$; Population 7, KUHE 16862-16863, 16865-16878 (16); Population 8, KUHE 25647-25656 ( $n=10)$. 